\title{
As transformações dos contratos
}

\author{
Lino de Morais Leme
}

\section{Origens e alteraçбes no regime contratual.}

Os contratos começaram com as trocas de objetos e de serviços, com o pagamento em espécie em relação àqueles, sendo gratuitos os segundos. As necessidades levaram ao estabelecimento da moéda, que representava uma cabeça de gado (pecunia). Com o descobrimento e o uso de metais, surgiu a moéda metalica, que representou uma verdadeira revolução no regime contratual. Surgem fórmas diversas de compra e venda - sob peso, medida, por amostras, por qualidade.

Outras revoluções no regime contratual resultaram da invenção da escrita, da substituição da moéda metálica pela fiduciária, do desenvolvimento do crédito.

Os contratos eram, a princípio, dominados por fatos materiais, que passaram a ser regulados pelo Estado. Não ha contrato sem a tradição real, mais tarde substituida pela simbólica: a tomada de posse por um terrão, um ramo de árvore, uma pedra. O empréstimo exigia que fosse pesada a qualidade de metal que o devedor se obriga a devolver. (1) No direito judaico não basta uma simples convenção para constituir uma sociedade; se o capital é em dinheiro, deve ser posto em um saco, que deve ser erguido pelos sócios. O mútuo era um favor que as pessôas se prestuvam

(1) O que se tornou mera formalidade, com a invenção da moeda. 
umas às outras; o próprio vocábulo mutuus significava, entre os romanos, ajuda mútua. Também o depósito e o mandato eram contratos gratuitos, como ainda é o comodato (Cód. civil, art. 1.248) e o depósito (art. $1.265 \S$ único), nas legislações modernas.

O contrato consensual era desconhecido, como sucedia no direito romano antigo - Ex nudo pacto actio non nascitur. Ele apareceu, nesse direito, como exceção, em relação a quatro contratos - compra e venda, arrendamento, sociedade e mandato. Em relação à compra e venda, porém, o domínio não se transfere pelo simples consenso -Traditionibus et usucapionibus, non nudis pactis, dominia transferuntur.

Do capitalismo surgem os juros. 0 erédito assume novas fórmas e a necessidade de garantias se apresenta.

Os costumes evolvem para a lei escrita, que permite a generalização de regras

\section{Abusas.}

Como fórma de pagamento da dívida se introduz a escravidão, que foi a primeira fórma de prestação de serviços. Os abusos determinam providências em favor dos devedores, e se proibe o contrato de locação perpétua de serviços, que em geral é limitado a prazos não muito longos (entre nós, o limite é de quatro anos). A exploração do devedor, por meio de taxas elevadas de juros, é coibida. Providências se tomam quanto à fixação dos preços, quando a ordem social as exigem. E contra outras fórmas de exploração, condenadas pela moral, se editam normas proibitivas.

\section{O Código Napoleão.}

Com o surto do individualismo, que caraterizou os séculos XVIII e XIX se extinguem as corporações, como 
contrárias à liberdade de trabalho. O contrato é um acôrdo de vontades, caraterizando-se a liberdade de cada um, com a expressão - autonomia da vontade; e tão forte ela é, que a lei declara ser o contrato lei entre as partes. Acima da vontade individual se colocam apenas os princípios de ordem pública. Outros dizem que os elementos dos contratos são o acôrdo de vontades, a ordem pública e os bons costumes; mas esse acôrdo de vontades tem a mesma significação. E, embora o contrato, como o ato jurídico, exija a liceidade do objeto, contudo não se pode omitir o carater de que ele constitui lei entre as partes, pois aí está a essência do mesmo.

Tão arraigado está esse princípio da autonomia da vontade, que se consideram as novas modalidades do contrato como constituindo o desconhecimento do mesmo, ou uma brecha nele aberta, pela concepção da vontade implícita, salientando-se que a essência dos contratos exige a discussão entre as próprias partes (2).

Para explicar as transformações, os escritores têm formulado teorias várias: o dirigismo contratual, ou a socialização, ou substituição do direito privado pelo direito p'úblico; a decadência, ou a violação, ou a crise do contrato; um ato regulamentar, ou convenção-lei, ou estatuto legal do contrato, ou a evolução deste para instituição; o solidarismo; a evolução da técnica do contrato, e talvez outras

\section{O dirigismo contratual.}

É a teoria de Josserand.

Em todos os tempos, houve intervenções governamentais em matéria contratual. No direito romano houve a

(2) ZARKSAS, Les transformations du contrat et leur loi, 1939,223

(3) Aperçu général des tendances actuelles de la théorie dea contrats (in Revue trimestrielle da droit civil - 1937). 
interdição, durante o Império, de exportar trigo, vinho; as intervenções destinadas a impôr às corporações comerciais, industriais e operárias, sob a fórma de obrigações imperativas, o regime sistemático de subordinação, que acabou generalizando-se; a tentativa de taxação das mercadorias pelo edito do máximo, e a fixação do salário, sob Deocleciano; a luta contra o precarium, que levou ao contrato feudal.

$\mathrm{Na}$ Grécia, as legislações de Licurgo e de Solon já teriam dado o exemplo da intervenção governamental, destinada a pôr fim às crises da época.

Que foram as leis de Moisés para os israelitas? Que são os plenos poderes concedidos aos chefes, em periodos considerados de salvação nacional, ou por estes assumidos, como se observa em vários países, atualmente?

Num dos países considerado a terra do liberalismo, os Estados Unidos da América, em 1890, o Sherman Act declarava ilícitas as coalisões formadas por trusts e carteis, com o objetivo de aumentar os preços; e outras leis se fizeram com o mesmo carater, especialmente o New Deal, fixando preços das mercadorias, estabelecendo limites à exportação, aos salários, controlando o câmbio, etc. $\mathrm{Na}$ Inglaterra, são limitadas as taxas de juros e se permite aos tribunais anular o contrato de empréstimo que lihe pareça duro e abusivo (harsh and unconcionable).

Alessandri (4) diz que a tendência é para o contrato dirigido, regulamentado e fiscalizado pelos Poderes Públicos, em sua formação, execução e duração, como consequência do regime de economia dirigida, e resultante das seguintes causas: a) o desenvolvimento das idéias socialistas; b) a formação de grandes grupos econômicos (sociedades, trusts, carteis, etc.) ; c) a crise produzida pela guerra 1914-1918.

(4) El contrato dirigido. 
Para Josserand, trata-se da poblicização do contrato.

Influenciado por suas idéias, Cunha Barreto (5) diz que "o conceito estatal moderno é incompativel com o liberalismo passado, em que o indivilduo se sobrepunha à coletividade, sacrificando-a aos seus interêsses. O Estado atual é uma incessante luta de integração social. Reflete, na sua estrutura, forças interdependentes, que congrega e comanda". No desenvolvimento dessas idéias, escreve: "Não era possivel sobreviver a velha teoria dos contratos, num cenário em que o indivilduo não se basta a si mesmo. Se se pretendesse resolver os problemas atuais com a liberdade contratual, a desordem seria inevitavel.. Não escapou aos juristas, mesmo os maìs arraigados à tradição, esse aspecto da vida contemporânea. Resistem alguns, como teólogos recolhidos ao tabernáculo do ramanismo, indiferentes ao culto do direito, na sua exterioridade atual". Recorda o conceito de Kelsen, de que "o contrato é um ato de participação estatal"; o de Carlos Schmidt; "O Estado e a Sociedade devem ser fundamentalmente idênticos; com isto todos os problemas sociais e econômicos se convertem em problemas políticos, e não cabe distinguir, já, entre zonas concretas politico-estatais e politico-sociais"; e de Agamemnon Magalhães:" A luta do Estado tem sido a luta pela autoridade, pela afirmação incontrastavel do seu poder. Não é poder como fim, mas poder como instrumento".

Para ele, a autonomia da vontade era fantasia, pois não existia na realidade. Pode-se dizer que mudaram as pessôas dos contratantes, que se não pode pretender um direito parado, que ha uma variedade de contratos antes desconhecidos. O dirigismo, segundo Josserand, é um esforço para a adatação dos contratos aos fenômenos econômicos e sociais imprevistos, devendo corresponder às razões de oportunidades e às necessidades práticas; mas quando fere direitos adquiridos, é um mal. Segundo esse escritor, esse deslocamento da teoria dos contratos, com base na liberda-

(5) Revista dos Tribunais. 117/455 
de e na autonomia da vontade, se verifica sob a influência: de causas profundas, entre as quais sobressaem duas uma de ordem político-juridica, e a outra especificamenteeconômica. Cunha Biarreto entende que mesmo nessa hipótese, o dirigismo contratual é um bem. Deixaria de sê-lo, e passaria a ser um mal, se deixasse de ser um fin, para. se transformar em instrumento de opressão, ultrapassando os limites da ordem juridica. E conclui: "Dirigismo fóra da lei, ou da interpretação jurisprudencial, é ilegalidade".

Santiago Dantas, (6) depois de lemibrar os princípios: gerais da doutrina dos contratos, diz que duas causas exercem pressões crescentes sobre a estrutura sistemática dos. contratos: a) o sentido solidarista, que prepondera na política contemporânea dos Estados democráticos; $b$ ) a intervenção crescente do Estado nas relações econômicas, para exercer, por orgãos próprios, um número cada vez maior de atividades. As leis anti-trusts já mostraram que a liberdade econômica não é um princípio absoluto. A política: solidarista se manifesta na proteção social dos mais fracos, no estabelecimento de normas restritivas da liberdade contratual. Destas, algumas são novos princípios de ordem pública (as leis de inquilinato, a de salário múnimo, a de fixação de preços, a de limitação das taxas de juros, etc.); nesses casos não se pode ver uma revogação do sistema contratual. Outras, porém, parecem pôr em xeque as concepções básicas da doutrina dos contratos, e que se não limitam a fixar total ou parcialmente o conteúdo dos contratos, mas chegam a criar a obrigação de contratar (a de vender, a de produzir, a de comprar (estas sobretudo nas subscrições compulsórias dos empréstimos públicos); mas não se trata aí de obrigações ex lege, isentas de qualquer ato voluntário, mas representam o último elo de uma cadeia de atos voluntários, e, embora prédeterminados, é à vontade que, em última análise, têm de ser imputados os seus efeitos. Essa feição solidarista determinou também o acolhimento da?

(6) Revista dos Tribunais, 195/544. 
cıausula rebus sic stantibus, por alguns códigos. Também é de se assinalar a intervenção do Estado, assumindo atividades paralelas às dos particulares. E conclui que a multiplicação das fórmas dos contratos prova a vitalidade do princípio da autonomia da vontade, apesar das múltiplas manifestações do interesse público, que se traduzem em limitações e regras coercitivas. Deve admitir-se a revisão dos contratos, quando as obrigações se tornarem excessivamente onerosas. É desejável um sistema de sanções eficazes para dar força obrigatória mais afetiva aos contratos concluidos entre empresas pertencentes ao Estado, ou por êle controladas, ou com organismos internacionais.

Arnoldo Medeiros da Fonseca, (7) considerando especialmente o problema de revisão dos contratos, conclui que o contrato, em sua fase atual, deixou de ser um ato exclusivamente privado, para constituir um fenômeno social, cuja existência e efeitos interessam não sómente às partes mas também à coletividade, do que provém a legitimidade de ser regulado pelo poder público.

Darcy Bessone (8) acredita que, resolvido o problema social, voltará o contrato a ter normas abstratas e permanentes, conferindo estabilidade às relações contratuais.

\section{Decadência do contrato?}

Entendem alguns que o fato de as novas orientações não se amoldarem ao contrato clássico, representa uma decadência, (9) uma crise, (10) ou uma violação do contrato, (11) como se ele houvesse atingido o seu apogeu, de onde sómente poderia sair, involuindo; e a involução é o

(7) Revista de diritto commerciale, de Sraffa e Vivants, ano

XLVIII, La forza obrigatoria dei contratti, p. 437.

(8) Aspetos da evolução da teoria dos contratos

(9) Morin, La loi et le contrat, 1927.

(10) Barreyre, L'évolution et la crise da contrat, 1937.

(11) Capitant, Le régime de la violatino da contrat, 1934. 
caminho da morte. "Socialiser, diz RtPert (12), c'est permettre au droit public de dominer la vie privée", e ele conclama todos para "sauver les hommes de la servitude des lois", apontando as revoltas contra a lei, a qual "n'est plus la volonté générale, mas l'expression de la force d'un parti".

Com o descobrimento das rotas marítimas e a intensificação do comércio, os contratos assumem novos aspectos, que a invenção da escrita, a moéda fiduciária, os bilhetes de banco, os saques, os cheques, o crédito, o telégrafo, o telefone levariam a um incremento extraordinário. $O$ formalismo contratual se atenúa, contratos existentes assumem aspectos novos e surgem outros, sem que em tempo algum se pudesse falar em decadência do contrato (13). As providências que, no século III, foram tomadas pelos imperadores, por motivo da depreciação do valor da moéda e da crise de produção, que determinaram uma alta formidável dos preços, não representaram uma decadência para o contrato, e sim a aplicação de medidas destinadas a restabelecer o equilibrio rompido na vida econômica, como se procura reconduzir ao equilíbrio o corpo humano, cujas condições hígidas foram perturbadas.

O formalismo rigoroso do contrato primitivo é também um sinal de intervenção estatal representado, em Roma, na compra e venda, por exemplo, pela figura do libripens. $O$ formalismo se atenúa, perdendo o carater que tinha; tornam-se remunerados contratos que eram gratuitos, e isso não representou uma degradação, ou decadência, involução ou crise do contrato, mas evolução, progresso.

Por isso muito bem disse Joseph Zarkoas (14) : a extensão do papel e da função do contrato caraterizam a evo-

(12) Fourgeaud (apud. Veniamin, Essais sur les données économiques dans l'obligation civile, 1931, p. 21

(13) de déclin du droit, 1949

(14) O. c., p. 34 . 
lução do contrato romano (15), que assinala os quatro fenômenos marcantes dessa transformação: $a$ ) rompimento do círculo estreito das relaçōes sociais, e maior participação do estrangeiro na vida privada; $b$ ) o desaparecimento dos agricultores pequenos e médios, que vão engrossar o proletariado, nas cidades; c) o desaparecimento das companhias publicanas, após a segunda guerra púnica; $d$ ) o desenvolvimento formidavel do papel da ordem equestre, no Estado, expresso por uma única consequência: o desaparecimento dos boni mores, como fator de bôa fé e equidade (15).

\section{Evolução da técnica do contrato.}

E a opinião de Sallé de la Marnière, e a de outros, embora divergindo quanto aos fundamentos dessa evolução.

É assim que ZARKSAS (16) vê dois planos nas transformações contratuais: o do processo para contratar, e o das soluções dos princípios contratuais; e duas inovações: uma, resultante da impossibilidade, em grande número de contratos, de discussão direta, e outra, decorrente da uniformização das relações e das cláusulas contratuais. As transformações resultam de três fatores: a) as idéias dominantes; b) as relações econômicas: c) o equilíbrio social.

Para SaAvedra (17), as transformações resultam de limitações à autonomia da vontade, por motivo de ordem pública, devendo-se, a essa orientação: a) a limitação dos arrendamentos; $b$ ) a proibição de renunciar aos direitos oriundos do contrato de trabalho; $c$ ) as modificações dos ef eitos e das consequências dos contratos; $d$ ) as alterações de contratos, pelas moratórias, redução dos proços dos arrendamentos, fixação dos preços máximos. Para êsse pro-

(15) Id. p. 42.

(16) O. c., p. 220 e seg., e 229.

(17) Novas orientações no direito das obrigações, e transformações dos contratos. 
fessor, deve manter-se uma prudente equidistância entre a autonomia da vontade $e$ a intervenção estatal, considerando o contrato apenas como um veículo para a circulacão da riqueza privada.

É em Savatier (18), porém, que mais claramente se acentua não ser o contrato apenas um testemunho da liberdade, mas igualmente uma técnica, dirigida pelo Estado, que substitui o contrato pela "relação do fato", empregando duas orientações: o contrato autorizado (formação de sociedades por ações) e o contrato regulamentado (quanto às pessôas dos contratantes e à quantidade, além das restrições (ou imposições) contratuais. O contrato é substituido por uma relação paracontratual, verificando-se a substituição progressiva do contrato pela instituição, na qual o principio da igualdade contratual cede progressivamente ao da hierarquia.

Já Duguit vê no solidarismo o fundamento das transformações dos contratos.

Para Décugis (19), a técnica moderna cria as entidades contratuais.

Veniamin (20) vê na colaboração a caraterística da obrigação moderna. O consentimento das partes não se funda mais sôbre as condiçc̃es econômicas da prestação, que faz o objeto do contrato; elas lhes são dadas pelo estado econômico do logar e do momento. O imperativo econômico decide o sentido da obra jurídica, já tendo feito cairem as barreiras entre o direito civil e o comercial.

(118) Les métamorphoses économiques et sociales du droit civil, p. 41 e ss.

(19) Les étapes du droit, 1946, p. 190.

(20) O. c., ps. 260, 306, 300, 333. 


\section{A autonomia da vontade.}

Dugurt (21) entende que não é a vontade das partes contratantes a fonte do vínculo obrigatório, e sim as manifestações da vontade, de acôrdo com a lei, para produzirem um determinado efeito jurídico.

Realmente, o que a lei exige é o acôrdo de vontades. Não se pode falar em autonomia da vontade, senão no sentido de que a vontade deve ser livre.

A autonomia da vontade não requer, porém, seja a vontade manifestada pelos indivíduos, pois têm capacidade para contratar as pessôas físicas e as pessôas jurídicas. Outra é a questão referente aos efeitos dos contratos destas - entre elas incluidos os grupos e entidades reconhecidas pela lei —, sobre os elementos que as integram.

Para explicar as novas técnicas, em matéria de contratos, não é mister derribar o ídolo que antes se adorava, dizendo-se que o contrato é apenas um meio para circular a riqueza, ou pretendendo-se que ele evolveu para a instituição, ou que o indivíduo é absorvido pelo Estado, tornando-se ele um elemento passivo, pois deve obedecer à direção dada pelo Estado:

A nova técnica contratual consiste nos contratos de adesão e nos de regulamentação, com exclusão dos contratos coletivos de trabalho. Por outro lado, vê-se o Estado intervir no domínio de certas atividades, impondo normas para o exercício de certos direitos.

Quanto aos primeiros, sem dúvida se trata de evolução da técnica contratual. Em relação às segundas, porém, o que se verifica é uma luta entre os princípios que dirigem as transformações do contrato. Em todos os casos, porém, se trata de fórmas resultantes de novos aspectos da vida econômica, ou de restaurar a igualdade, que é a base em que assentam as relações contratuais.

(21) Las transformaciones generales del derecho privado. 


\section{A nova técnica contratual.}

O Estado não pode desempenhar todos os serviços reclamados de sua atividade econômica, e cujo interêsse se vê com esta simples expressão - serviços públicos. O serviço de fôrça e luz e o de transporte, por exemplo. Então o Poder Púlblico concede a uma empresa o direito de explorá-lo por um tempo limitado, fazendo com a mesma um contrato - concessão, com base no qual a empresa se obriga a pôr o serviço à disposição do público, mediante determinadas condições. O mesmo ocorre com o serviço de transporte. Quem se utiliza desses serviços, ou dá uma simples adesão ao contrato — pedindo a ligação de fôrça e luz ou comprando a passagem que lhe dá direito ao transporte - ou faz um contrato, com base no contrato - concessão.

A celeridade dos negócios levou a extender essa fórma de contratar a outros contratos, como em matéria de seguros.

Essa maneira de se operar o acôrdo de vontades não veiu a significar que o mesmo seja dispensado.

Quando, em nosso organismo, um coração se torna fraco, surgem as defesas orgânicas para reforçá-lo. Também na vida social, quando os individuos sentiram-se fracos, procuraram defender-se: daí as associações, a uma classe das quais foi reconhecido o direito de representar os seus componentes, como a outras entidades às quais foi reconhecida a personalidade jurídica.

Porventura não se verifica o acôrdo de vontades, por essa fórma? Acaso os que fazem parte de um sindicato são compelidos, manü militari, a trabalhar para os patrões com as quais foi feito o contrato coletivo? E o patrão não se pode desligar de seu sindicato, se não estiver de acôrdo com a orientação que o mesmo haja tomado.? 


\section{Os princípios que regem a evolução dos contratos.}

Houve época em que se fundava o direito em Deus. Depois surgiu a concepção do direito natural, no qual uma corrente vê a sobrevivência da inspiração divina. Veiu mais tarde a escola histórica, que sustenta resultar o direito da vida social.

Ligado o direito, a princípio, à religião e à moral, e constituindo ele as regras de conduta necessárias para o equilíbrio social, era natural a luta entre a emanação do egoismo humano e os princípios morais, manifestação do altruismo, outra fôrça gerada pela primeira. Do jogo de ambas resultou o equilíbrio social. A economia é uma das fórmas do utilitarismo, e a colaboração, ou a solidariedade, é uma das expressões do altruismo.

Alguns escritores querem fundar a vida social apenas no interêsse esconômico, que é uma fôrça egoística, e outros na solidariedade, ou colaboração, que é uma fôrça altruística, oposta à primeira. Ora: a vida social é uma resultante de ambas.

Acima delas, os filósofos dos séculos XVIII e XIX, dominados pela preocupação individualista, colocaram a liberdade. É a resurreição do princípio romano, segundo o qual a vontade era a criadora do direito, sendo até o Estado considerado communis reipublicae sponsio, não considerando eles as relações jurídicas em que deve predominar a vontade social, ou seja a vontade individual, submetida à natureza e ao fim da sociedade. A existência das corporações, às quais era submetida a vontade individual, apresenta-se como a Bastilha, a ser destribuida em matéria contratual. O princípio da liberdade de trabalho leva a olvidar mesmo que o contrato é um acôrdo de vontades, ou seja equilíbrio entre os interêsses contrários, e se proclama a autonomia da vontade, como requisito para êle. É o predominio da doutrina racionalista de Rousseau, con- 
sagrada pela Revolução Francesa e pelo Código Napoleão, em seu duplo aspecto - político e civil. Daí a regra de que: o contrato é lei entre as partes, distinguindo-se a segunda da primeira, porque a vontade das partes não pode contrariar os princípios de ordem pública.

É pertinente, pois a observação de Duguit, de que não é a vontade das partes contratantes a fonte do vínculo obrigatório, e sim, as manifestações da vontade, de acôrdo com a lei, para produzirem um determinado efeito jurídico. (22) Assim, pode ela emanar de todos aqueles que tenham capacidade para contratar, na fórma da lei. Outra é a questão quanto aos efeitos dos contratos sôbre os elementos que integram as entidades às quais a lei confere capacidade para contratar.

Joseph ZaRKsas (23) procura demonstrar que a evolução dos contratos resulta das transformações econômicas, verificando-se a adaptação dos contratos às condições da vida social, ao ideal moral, ao novo equilíbrio social. Ele se aproxima da verdade -, mas se esquece de apontar as causas desse equilíbrio social, desse novo direito contratual, pois apela para um princípio misterioso, que é, afinal, a adaptação (24).

$O$ equilíbrio social se verifica quando as fôrças que se encontram são iguais. Daí o procurar a sociedade, instintivamente, colocar as partes em situação de igualdade. Se procuramos discernir, na história dos povos, o sentido profundo das transformações do regime contratual, parece que podemos descobri-lo nessa procura obstinada da igualdade entre os contratantes, diz Decugis (25)

Quais as fôrças, porém, que se encontram em luta, e cujo equilíbrio é encontrado na igualdade? A nosso ver,
(22) O. c.
(23) O. c., p. 55
(24) O. c., ps. 128 e 134
(25) O. c., p. 125 
são as fôrças egoísticas, representadas pelos interêsses particulares, e as fôrças altruistas, representadas pelos interêsses gerais, ou seja entre a vontade individual e a vontade social, entre o interêsse econômico e o moral.

Quando a vida econômica se modifica, instala-se um desiquilíbrio, pelo desajustamento dos elementos conservategram, e a luta se instaura entre os elementos conservadores e renovadores, até se alcançar a nova fórma de equilíbrio, sem o qual não é possivel a vida social, que é toda. fundada em relações obrigacionais. Daí o haverem os escritores encontrado uma relação constante entre a evolução dos contratos e os fenômenos sociais.

A nova técnica contratual é, no domínio social, a aplicação do principio biológico de que a função faz o órgão. O desenvolvimento da função determina a formação de novos orgãos, para o exercício da mesma. Aí não se contrapõem as fôrças que levam ao equilíbrio social, pois aí não se configura a luta entre a vontade individual e a vontade social, representada pelas condições de vida e desenvolvimento da sociedade.

\section{A intervenção estatal.}

Guilhermo Cabanellas (26) diz que o erro essencial' do Código francês foi o haver confundido igualdade jurídica e igualdade econômica, e que esta tem determinado a constante ingerência do Estado, inclusive nos contratos privados. E acrescenta que, na Argentina, o princípio da autonomia da vontade, expresso no artigo 1.197 do Código civil, tem escassa aplicação, porquanto as convenções trabalhistas não podem desconhecer ou eliminar as bases substânciais do Direito de Trabalho.

Como se vê, ha uma tendência em combater a interferência da vontade, na formação dos contratos. Para Duguit,

(26) Los fundamentos del nuevo derecho, 1945. 
cada homem, cada grupo tem uma tarefa a exercer no corpo social, sendo a função de cada qual determinada pela situação de fato que ocupa na coletividade. O direito subjetivo é uma abstração sem realidade. A função de cada um tem um valor social e é socialmente protegida. Para outro, o contrato é apenas uma fórmula para a circulação da riqueza.

O Código civil soviético não elimina a proteção à vontade individual, mas declara que os direitos civís são pro-tegidos, exceto no caso de se exercerem em sentido contrário à sua finalidade econômica e social (27).

Pode a lei, como sucede nesse direito, estabelecer um. princípio, deixando aos juizes o encargo de aplicá-lo nunca, porém, a organismos estabelecidos por uma ditadura -, ou estabelecer as normas impostas pela igualdade: social. Sim, porque a igualdade individual deve agir em: função da igualdade social.

Quando num país, como a Inglaterra, as leis são principalmente o resultado da atividade dos elementos aos. quais é concedido o poder judicante, podem eles corrigir as perturbações resultantes da desigualdade social, reconhecendo os organismos que se constituiram pela união das: fôrças individuais. Nos paises ocidentais, porém, êsses poderes constam de leis.

No Brasil, a Constituição federal preceitúa que a ordem. econômica deve ser organizada conforme os princípios da justiça social, conciliando a liberdade de iniciativa com a valorização do trabalho humano (art. 145). E à União se faculta, mediante lei especial, intervir no domínio econômico, e monopolizar determinada indústria ou atividade, tendo por base o interêsse público, e por limite os direitos: fundamentais assegurados na Constituição (art. 146).

Com base nesse segundo artigo, veiu a lei que autoriza. o Poder Executivo a intervir no dominio econômico, com--

(27) Cód. civil, art. 1.0 
prando, distribuindo e vendendo, fixando preços e o contrôle do abastecimento, desapropriando bens ou requisitando serviços.

O abuso do poder econômico foi também coibido pela fixação de salário mínimo para os trabalhadores, e com o reconhecimento do contrato coletivo de trabalho, superintendido pelo Ministério de Trabalho, ao qual ainda se tribuem outros poderes, com o fim de impedir que a lei seja desvirtuada em sua aplicação. Além disso, o Código Penal define crimes contra a organização do trabalho (art. 197 e ss.).

O direito romano considerava ter o vício da lesão a compra e 'venda, quando o preço pago era inferior à metade do valor (1. 2 C. (1-44), além da lesão na partilha ( $\mathrm{L}$. $3 \mathrm{C}(3-38)$, devido à influência do estoicismo e do Cristianismo; mas não figura em geral nos contratos. $\mathrm{O}$ Cód. espanhol reconhece alguns casos de lesão (contratos feitos por tutores, os celebrados em representação de ausentes), mas dispõe, no art. 1.293, que nenhum contrato poderá ser rescindido por lesão, fóra desses casos. O Código francês, porém, conservou os princípios romanos, estabelecendo haver lesão, na compra e venda, quando de importância superior a $7 / 12$, e, na partilha, a $1 / 4$ (arts. 16814 e 887 ). O Código suiço subordina a lesão à desproporção evidente, "si la lésions été déterminée par l'exploitation de sa gêne, de sa légèreté on de son inexpérience" (art. 21 do Código civil).

Entre nós, a lesão era distinguida em enorme e enormíssima, pelas Ordenações Filipinas, sendo aquela correspondente a mais da metade do valor, e não se definindo a segunda. O Código Civil, porém, não considerou a lesão um defeito do ato jurídico, de maneira que ela ficou dependendo da existência de erro ou dolo. O Código Penal, porém, considera crime abusar de necessidade, paixão ou inexperiência de menor, ou da alienação ou debilidade mental de outrem, induzindo-o à prática de ato suscetivel 
de produzir efeito jurídico, em prejuizo próprio ou de terceiro.

Com o propósito de restabelecer a igualdade entre as partes, manifesta-se também a tendência em se admitir o princípio rebus sic stantibus, que, como o da lesão, foi inspirado pelo direito canônico. A princípio se tolerava a aplicação do mesmo apenas em matéria de serviço público. Diversas leis, porém, fizeram aplicações outras (a que proibe aumento de alugueres e prorroga contratos de locação, a que reduz as taxas de juros, a que dispõe sôbre obrigações em moéda estrangeira, a que fixa o valor do mil reis ouro, etc.). O Código da Polónia veiu a consagrar o princípio, que o Ante-projeto de Código de obrigações inscreveu (art. 322), e que o novo Código Civil italiano também reconhece, não prescrevendo a revisão, mas admitindo-o para a resolução dos contratos (art. 1457 e ss.)

\section{A rontade individual e a vontade social.}

Como se disse, o contrato exigia o acordo das vontades. Não a autonomia, mas a liberdade: a vontade livre.

Porventura, com as transformações operadas no regime contratual, desapareceu a liberdade contratual, essa liberdade tão necessária para o desenvolvimento em geral?

Como na esfera política, a liberdade contratual deve ser regulada. Como naquela, devem ser punidos os atentados a essa liberdade.

$\mathrm{Na}$ esfera política, a liberdade é regulada pela igualdade. Igualdade de direitos e de deveres. E coibidos e punidos são os atentados contra essa igualdade, necessária para se manter a fôrça espiritual, que a todos une em torno da idéia de Pátria.

No campo econômico, ha também uma fôrça, que determina o equilíbrio social, e que é resultante de duas outras: uma, que pretende o domínio do egoísmo, ou seja 
o do indivíduo, e outra que pretende impôr o altruismo, ou seja o interêsse coletivo. É nesse caso que se impõe a intervenção da coletividade, por seu Poder Legislativo, estabelecendo as normas a que deve obedecer e atividade dos indivíduos, ou grupos, e a intervenção do Poder Executivo, como supervisor, e a do Poder Judiciário, para punir os transgressores da norma.

Com essas leis, coibindo o abuso do poder econômico, não há dispensa do acôrdo de vontades, para a formação dos contratos, e sim o estabelecimento de normas que devem reger a vida contratual, de maneira a ficar assegurado o princípio da igualdade, subordinando-se a vontade individual à vontade social.

As leis que vedam a lesão procuram impedir que prevaleça o egoismo.

Na legislação ordinária se isenta de culpa o inadimplemento da obrigação, por motivo de caso fortuito ou de fôrça maior. Esse princípio se vem desenvolvendo no sentido de igualmente se considerar sem culpa o inadimplemento, quando o mesmo resulta de acontecimentos extraordinários, que nullum humanum consilium praevidere potest: daí a possibilidade de ser o contrato rescindido, sem a consequente responsabilidade por perdas e danos. 